\title{
Massive Dextromethorphan Ingestion and Abuse
}

\author{
TIMOTHY R. WOLFE, MD, E. MARTIN CARAVATI, MD, MPH*
}

\begin{abstract}
The case of a 23-year-old man who was acutely intoxicated on dextromethorphan and who was chronically addicted to the drug is described. He consumed the highest daily dose for the longest duration yet reported in the world's English-language medical literature. Toxicity, abuse potential, and therapy of dextromethorphan intoxication are discussed. (Am J Emerg Med 1995;13:174-176. Copyright (c) 1995 by W.B. Saunders Company)
\end{abstract}

Dextromethorphan (d-3-methoxy- $\mathrm{N}$-methylmorphine) is a cough suppressant available in many over-the-counter medications. It is an analog of the opiate family, but is thought to have no analgesic or addictive properties and its toxicity is presumed to be quite low. ${ }^{1}$ There have been sporadic reports of acute dextromethorphan ingestions in the world's medical literature, but not enough to warrant its international control as a narcotic. ${ }^{2}$ We describe a case of acute intoxication with dextromethorphan in a regular abuser who was strongly psychologically addicted to the drug.

\section{CASE REPORT}

A 23-year-old man was transported via ambulance to the hospital after being found in a snowbank "agitated and hallucinating." The patient had been on his way to group therapy, which he attended for an addiction to dextromethorphan, when he became exhausted and lay down. Before leaving for the meeting he had consumed three 12-ounce bottles of cough syrup (Robitussin DM [AH Robins, Richmond, VA]) ( $2160 \mathrm{mg}$ or $31 \mathrm{mg} / \mathrm{kg}$ ) and "several" beers.

Examination showed a somnolent and easily distracted patient who required frequent stimulations to provide a history. He was mildly confused; he was oriented to name and year but not to month or location. His speech was thick and slurred. Vital signs were: blood pressure $164 / 104 \mathrm{~mm} \mathrm{Hg}$, pulse 86 beats/min, respirations 18 breaths $/ \mathrm{min}$, and temperature $37.3^{\circ} \mathrm{C}$. His skin was hot and markedly diaphoretic. The pupils were $5 \mathrm{~mm}$ and reactive bilaterally. Horizontal and vertical nystagmus was present. There was no ophthalmoplegia. Mucous membranes were moist. Respiratory, cardiac, and abdominal examination results were normal. Extremities revealed marked tremulousness with fasciculations of the quadriceps muscles and hypertonicity. The patient's neurological examination showed marked ataxia; his gait was wide based, pigeon-toed and flat footed. He leaned forward, stumbled, and required assistance to prevent falling forward or sideways. He was unable to perform rapid alternating movements or finger-to-nose testing. The remainder of his neurological examination was normal.

From the Division of Emergency Medicine, University of Utah School of Medicine, and the *Utah Poison Control Center, Salt Lake City, UT.

Manuscript received July 1, 1994; revision accepted July 14 , 1994.

Address reprint requests to Dr Wolfe, Emergency Department, University of Utah Hospital, 50 North Medical Drive, Salt Lake City, UT 84132.

Key Words: Dextromethorphan, toxicity, abuse.

Copyright (c) 1995 by W.B. Saunders Company

0735-6757/95/1302-0013\$5.00/0
The patient received $50 \mathrm{~g}$ activated charcoal orally, $100 \mathrm{mg}$ intravenous thiamine and two 1-mg doses of intravenous naloxone. There were no acute changes in his symptoms or physical findings after this therapy. Over the next three hours, he gradually developed an increased ability to concentrate and provided a more reliable history. A blood and urine toxicology screen showed no evidence of alcohol, stimulant amines, opiates, cocaine, barbiturates, benzodiazepines, tricyclic antidepressants, or salicylates. Serum phencyclidine (PCP) and bromide were not evaluated. Liver transaminase, alkaline phosphatase, and lactic dehydrogenase were normal; creatinine phosphokinase was mildly elevated at $244 \mathrm{IU} / \mathrm{L}$. Chemistry panel showed sodium $138 \mathrm{mmol} / \mathrm{L}$, potassium $4.1 \mathrm{mmol} / \mathrm{L}$, chloride $104 \mathrm{mmol} / \mathrm{L}$, bicarbonate $22 \mathrm{mmol} / \mathrm{L}, \mathrm{BUN} 8 \mathrm{mg} / \mathrm{dL}$, creatinine 1.6 $\mathrm{mg} / \mathrm{dL}$, glucose $98 \mathrm{mg} / \mathrm{dL}$, serum osmolality $280 \mathrm{mOsm} / \mathrm{kg}$, calcium $9.2 \mathrm{mg} / \mathrm{dL}$. Hemoglobin was $14.7 \mathrm{~g} / \mathrm{dL}$, white blood count was $15,700 \mu \mathrm{L}$. His electrocardiogram revealed notched $\mathrm{T}$ waves and prominent $U$ waves in leads $I$, II and $V_{2}-V_{6}$, consistent with drug, electrolyte, or central nervous system (CNS) abnormality.

In further discussion, the patient divulged a prolonged history of cough syrup abuse. He consumed three to four 12-ounce bottles of Robitussin DM daily during the last two years and frequently during the previous five years. In addition, he drank a 6-pack of beer a day. He denied any other drug use or abuse. Despite this addiction, he had performed well in college, graduating with honors. At times, he had held responsible jobs, but he was now reduced to shoveling sidewalks and shoplifting his abused substances. His dextromethorphan and alcohol abuse history was confirmed by his brother. A review of systems showed numerous symptoms that occurred daily: unstable gait, restlessness, increased intensity of perceptions, blurred vision, nausea, vomiting, shivering, severe insomnia, slurred speech, tremors, "comfortably numb" sensation, floating and flying sensations, forgetfulness, visual and auditory hallucinations, and dysphoria and severe craving after drug withdrawal.

The patient was admitted for observation and his symptoms resolved overnight. No overt evidence of drug withdrawal occurred. The psychiatrist considered the patient clinically depressed with overlying substance addiction and abuse. The patient was discharged to follow up with substance abuse counseling.

\section{DISCUSSION}

This case describes the highest daily dextromethorphan consumption for the longest time yet reported (36 to 48 ounces of Robitussin DM a day, or 2160 to $2880 \mathrm{mg}$ dextromethorphan hydrobromide for up to 5 years). The case shows the potential toxic and addictive properties of this drug.

Including this case, there are 16 patients with acute dextromethorphan intoxication described in the world's English-language medical literature. ${ }^{3-12}$ Most cases were unintentional ingestions by children. CNS manifestations are the primary presenting symptoms of patients acutely intoxicated on dextromethorphan and consist of altered mental status (ranging from somnolence to hyperexcitability), ataxia, and nystagmus. Table 1 summarizes the physical symptoms reported in these 16 patients.

Originally thought to have little or no significant toxic ef- 
TABLE 1. Symptoms of Acute Dextromethorphan Toxicity in Reported Cases (Including This Report)

\begin{tabular}{ll}
\multicolumn{1}{c}{ Symptoms } & No. of Patients \\
\hline CNS Effects & \\
Hyperexcitability and restlessness & 6 \\
Lethargy or somnolence & 7 \\
Ataxia & 7 \\
Slurred speech & 2 \\
Tremors/fasiculations & 1 \\
Hyperreflexia/Hypertonic & 2 \\
Ophthalmologic Effects & \\
Nystagmus & 7 \\
Pupillary changes & \\
$\quad$ Pin point & 1 \\
$\quad$ Normal & 3 \\
$\quad$ Dilated & 3 \\
Other & \\
Diaphoresis & 2 \\
Hypertension & 3 \\
\hline
\end{tabular}

NOTE: Many case reports did not describe the physical findings completely; the symptoms listed here were reported out of a total of 16 patients with acute intoxication.

fects and to be "devoid of addiction liability," dextromethorphan was developed and marketed in the 1960 s as an overthe-counter antitussive medication. ${ }^{13,14}$ Since that time, widespread abuse has been reported in a number of areas in the world. In the $1960 \mathrm{~s}$, a tablet form of pure dextromethorphan, Romilar, was withdrawn from the market because of increasing abuse within the drug counterculture. In 1986, the Swedish National Board of Health and Welfare forced dextromethorphan into prescription drug status because of teenage abuse of the product. ${ }^{15}$ An epidemic of adolescent and teenage abuse of dextromethorphan in Utah in the $1980 \mathrm{~s}$ resulted in voluntary removal of the drug from store shelves to behind pharmacy counters. ${ }^{16}$ Most recently, physicians in Charleston, South Carolina, have noted increasing abuse of dextromethorphan in the teenage population. ${ }^{12}$ All the case reports of intentional abusers, ${ }^{6,10,11,12,17-21}$ including ours, showed signs of prolonged addiction (3 months to years). Most patients describe acute euphoria after consumption, with intense craving and dysphoria on withdrawal. No physical withdrawal symptoms are reported. The primary psychological symptoms noted by the abusers are listed in Table 2. Many of these symptoms were related to us by our pa-

TABLE 2 Psychological Symptoms of Dextromethorphan Intoxication and Withdrawal

\begin{tabular}{ll}
\hline \multicolumn{1}{c}{ Acute Intoxication } & \multicolumn{1}{c}{ Withdrawal } \\
\hline Euphoria & $\begin{array}{l}\text { Difficulty Sleeping } \\
\text { Dysphoria and Depression }\end{array}$ \\
Altered Time Perception & \\
Feelings of floating & \\
Tactile Hallucinations & \\
Visual Hallucinations & \\
Auditory Hallucinations & \\
Visual Disturbances & \\
Paranoia & \\
Disorientation & \\
\hline
\end{tabular}

tient. The marked dysphoria and depression as intoxication abated seemed to be the driving force for our patient's continued abuse of the drug.

Experimental evidence in animal models suggest that the physical effects of DM and its abuse potential are caused by the active metabolite dextrorphan. ${ }^{22,23}$ This metabolite binds the same CNS receptor as PCP, and animals exhibit similar activity if given either drug. The level of the dextrorphan metabolite is highly variable; $5 \%$ to $10 \%$ of Caucasians lack the enzyme to make it, whereas in others there is extensive metabolism. ${ }^{14,24-26}$ The authors of this research ${ }^{22,23}$ suggest that individual genetic differences in demethylation may explain the vulnerability of some patients to the addictive effects of dextromethorphan.

\section{Therapy}

Acute dextromethorphan intoxication is short-lived and amenable to supportive care. However, three adults deaths have been reported in which dextromethorphan had been ingested and may have contributed to demise, ${ }^{15,27}$ and an additional 120 fatalities have been reported in which dextromethorphan was an exposure. ${ }^{28}$ Toxicity may be markedly increased if a long-acting form is ingested. ${ }^{29}$

There is no experimental evidence for or against charcoal use in dextromethorphan ingestion; however, charcoal is known to adsorb opiates, ${ }^{30}$ and dextromethorphan is an opiate analog. Gastric lavage in a liquid ingestion is likely to be of little benefit unless performed immediately, and potential risks such as aspiration and gastric or esophageal rupture exist. $^{31}$

The value of naloxone use in dextromethorphan toxicity is debatable. Its use in dextromethorphan intoxication was first reported in 1977 when it was given to an alert 22-month-old girl who was suffering excitability and ataxia. ${ }^{8}$ She had "distinct and rapid resolution of her ataxia" after administration of $0.005 \mathrm{mg} / \mathrm{kg}$ of naloxone. However, "the remainder of her neurological symptoms resolved within eight hours." Since that publication, four other authors have reported naloxone use with mixed results. ${ }^{3,4,5,12}$ One somnolent 3 -year-old patient "awoke" after its use. ${ }^{5}$ A second patient suffering coma and near respiratory arrest during a severe asthma exacerbation had pinpoint pupils and was given naloxone. ${ }^{4}$ Her mental status improved over three minutes and markedly improved over a longer time period. Subsequently, she was found to have no detectable narcotics on toxicology screening, and a history of 720-mg dextromethorphan use over the preceding 36 hours. An 11-week-old baby with hyperexcitability and hypertonicity after overmedication with dextromethorphan was "noted to be calmer" within 30 minutes of naloxone administration, and markedly improved over two hours. ${ }^{3}$ Finally, a 14-year-old boy who had ingested 4 ounces of Robitussin and was combative in the emergency room was given $2 \mathrm{mg}$ naloxone but "remained disoriented and slow to respond for approximately 5 hours." 12 A total of $2 \mathrm{mg}$ intravenous naloxone had no noticeable effect on our patient's somnolence or symptomatology. His mental status did improve slowly during his several-hour emergency department evaluation.

Dextromethorphan hydrobromide can also cause bromide poisoning. ${ }^{32}$ Typical symptoms of bromide toxicity include impaired CNS function including behavioral changes, head- 
ache, apathy, irritation, slurred speech, psychosis, tremulousness, ataxia, hallucinations and, eventually, coma. Weight loss and acneiform rash may also occur. ${ }^{31}$ Patients with these symptoms and coma require immediate dialysis for bromide removal. Bromide toxicity can be confirmed by a serum bromide level.

Other potentially serious toxidromes must be considered in the differential diagnosis. The differential for patients presenting with altered mental status, ataxia and nystagmus includes PCP, lithium and anticonvulsant toxicity (phenytoin, carbamazepine), thiamine depletion (Wernicke Korsakoff syndrome), sedative-hypnotic withdrawal, and toxic alcohol ingestion (isopropyl alcohol, methanol and ethylene glycol).

\section{SUMMARY}

In summary, this case represents the longest duration and highest daily dose of dextromethorphan abuse reported in the world's English-language medical literature. From the experience of this patient and the other reported cases, it is clear that dextromethorphan can cause significant psychological dependence but does not seem to cause any physical dependence. Many of the effects of dextromethorphan intoxication are likely caused by its active metabolite, dextrorphan. This metabolite causes physical symptoms similar to acute PCP ingestion. In addition, genetic variability in dextromethorphan metabolism may predispose some patients to addiction because of higher levels of dextrorphan metabolite. CNS manifestations, which are the primary presenting symptoms of patients acutely intoxicated on dextromethorphan, most frequently consist of altered mental status (ranging from somnolence to hyperexcitability), ataxia, and nystagmus. Supportive care seems to be all that is necessary, although care must be taken in the severely intoxicated. The role of naloxone is unclear, but its use has not been reported to cause any adverse effects. Bromide poisoning should be considered and investigated in the chronic abuser if symptoms and laboratory abnormalities suggest its presence.

\section{REFERENCES}

1. Gilman AG, Rall TW, Nies AS, et al (eds): Goodman and Gilman's The Pharmacological Basis of Therapeutics (ed 8). New York, NY, MacMillan, 1990, p 518

2. Eddy NB, Friebel $\mathrm{H}$, Halbach $\mathrm{H}$ : Codeine and its alternates for pain and cough relief. Bull World Health Organ 1969;40:657660

3. Pender ES, Parks BR: Toxicity with dextromethorphancontaining preparations: A literature review and report of two additional cases. Pediatr Emerg Care 1991;7:163-165

4. Schneider SM, Michelson EA, Boucek CD, et al: Dextromethorphan poisoning reversed by naloxone. Am $\mathrm{J}$ Emerg Med 1991;9:237-238

5. Katonia B, Wason S: Dextromethorphan danger. N Engl J Med 1986;314:993

6. Dodds A: Toxic psychosis due to dextromethorphan. Med J Austr 1967;2:231 (letter)

7. Myer $P$, Bryant B, Cartwright GW: Overdose with a combination decongestant, antihistamine and antitussive syrup. Indiana Med 1985;78:766-768
8. Shaul WL, Wandell M, Robertson WO: Dextromethorphan toxicity: Reversal by naloxone. Pediatrics 1977;59:117-119

9. Henretig $F$, Cugini D, Durbin $D$, et al: Dextromethorphan overdose in children. Vet Hum Toxicol 1988;30:364 (abstr)

10. Craig DF: Psychosis with Vicks Formula 44-D abuse. Can Med Assoc J 1992;146:1199-2000

11. Walker J, Yatham LN: Benylin (dextromethorphan) abuse and mania. BMJ 1993;306:896

12. Murray $S$, Brewerton T: Abuse of over-the-counter dextromethorphan by teenagers. South Med J 1993;86:1151-1153

13. Isbell H, Fraser HF: Actions and addiction liabilities of dromoran derivatives in man. J Pharmacol Exp Ther 1953;107:524530

14. Reynolds JEF, ed. Martindale: The extra pharmacopoeia (ed 29). London, UK, The Pharmaceutical Press, 1989, p 908

15. Rammer L, Holmgren $P$, Sandler H: Fatal intoxication by dextromethorphan: A report on two cases. Forensic Sci Int 1988; 37:233-236

16. McElwee NE, Veltri JC: Intentional abuse of dextromethorphan (DM) products: 1985 to 1988 statewide data. Vet Hum Toxicol 1990;32:355 (Abstr)

17. Degkwitz R: Dextromethorphan (Romilar) Als Rauschmittel. Der Nervenarzt 1964;35:412-414

18. Fleming PM: Dependence on dextromethorphan hydrobromide. BMJ 1986;293:597

19. Helfer J, Kim OM: Psychoactive Abuse Potential of Robitussin DM. Am J Psychiatry 1990;147:5

20. Orrell MW, Campbell PG: Dependence on dextromethorphan hydrobromide. BMJ 1986;293:1242-1243

21. McCarthy JP: Some less familiar drugs of abuse. Med $J$ Aust 1971;20:1078-1081

22. Szekely Jl, Sharpe LG, Jaffe JH: Induction of phencyclidine-like behavior in rats by dextrorphan but not dextromethorphan. Pharmacol Biochem Behav 1991;40:381-386

23. Tortella FC, Pellicano M, Bowery NG: Dextromethorphan and neuromodulation: old drug coughs up new activities. Trends Pharmacol Sci 1989;10:501-507

24. Pfaff $G$, Briegel $P$, Lamprecht I: Interindividual variation in the metabolism of dextromethorphan. Int J Pharmacol 1983;38: 618-624

25. Schmid B, Bircher J, Preisig R, et al: Polymorphic dextromethorphan metabolism: co-segregation of oxidative O-demethylation with debrisoquin hydroxylation. Clin Pharmacol Ther 1985;38:618-624

26. Hildebrand M, Seifert $W$, Reichenberger A: Determination of dextromethorphan metabolizer phenotype in healthy volunteers. Eur J Clin Pharmacol 1989;36:315-318

27. Kintz $P$, Mangin P: Toxicological findings in a death involving dextromethorphan and terfenadine. Am J Forensic Med Pathol 1992;13:351-352

28. McElwee NE, Beltri JC: Medical examiner reports of dextromethorphan exposures in the drug abuse warning network. $J$ Clin Res Pharmacoepidemiol 1991;5:167

29. Delvin KM, Hall AH, Smolinske SC, et al: Toxicity from long-acting dextromethorphan preparations. Vet Hum Toxicol 1985;28:296 (Abstr)

30. Mofenson HC, Caraccio TR, Greensher J, et al: Gastrointestinal dialysis with activated charcoal and cathartic in the treatment of adolescent intoxications. Clin Pediatr 1985;24:678684

31. Goldfrank LR, Flomenbaum NE, Lewin NA, et al: Goldfrank's Toxicologic Emergencies (ed 4). Norwalk, CT, Appleton and Lange, 1990

32. Ng YY, Lin WL, Chen TW, et al: Spurious hyperchloremia and decreased anion gap in a patient with dextromethorphan bromide. Am J Nephrol 1992;12:268-270 